\title{
TRPV6 Calcium Channel Inhibitor SOR-C13
}

National Cancer Institute

\section{Source}

National Cancer Institute. TRPV6 Calcium Channel Inhibitor SOR-C13. NCI Thesaurus.

Code C101525.

An inhibitor of transient receptor potential cation channel vanilloid family member 6

(TRPV6, CaT1 or CATL) with potential antineoplastic activity. TRPV6 calcium channel inhibitor SOR-C13 binds to TRPV6 and prevents the influx of calcium ions into TRPV6expressing tumor cells. This inhibits the activation of nuclear factor of activated T-cell (NFAT) transcription complex which may result in an inhibition of calcium-dependent cancer cell proliferation and an induction of apoptosis in tumor cells overexpressing TRPV6. The TRPV6 ion channel plays a key role in calcium homeostasis and is highly selective for calcium compared to other cations; it is overexpressed in a variety of tumors and initiates tumor cell growth, proliferation and metastases. 